\title{
Awakening - Transformation, agency and virtue from three contemporary philosophical inspirations: Bhaskar, Segal and Slote
}

\author{
Author: \\ Dudley Schreiber ${ }^{1}$ \\ Affiliation: \\ ${ }^{1}$ Research Student, Christian \\ Spirituality, University of \\ South Africa, South Africa \\ Correspondence to: \\ Dudley Schreiber \\ Email: \\ dasch101@gmail.com \\ Postal address: \\ 81, 10th Street Orange Grove \\ 2192, South Africa \\ Dates: \\ Received: 30 Mar. 2015 \\ Accepted: 29 Apr. 2015 \\ Published: 30 Oct. 2015 \\ How to cite this article: \\ Schreiber, D., 2015, \\ 'Awakening - Transformation, \\ agency and virtue from three \\ contemporary philosophical \\ inspirations: Bhaskar, Segal \\ and Slote', HTS Teologiese \\ Studies/Theological Studies \\ 71(1), Art. \#2974, 10 pages. \\ http://dx.doi.org/10.4102/ \\ hts.v71i1.2974

\section{Copyright:} \\ (C) 2015. The Authors. \\ Licensee: AOSIS \\ OpenJournals. This work is \\ licensed under the Creative \\ Commons Attribution \\ License.
}

Read online:

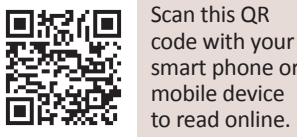

For some, 'transformation' is the new non-reductive and non-normative 'development', attracting attention from interdisciplinary array, but of particular theoretical and practical interest to Spirituality scholars. In philosophical context, transformation theory has suffered greatly from 'agency-structure' dualism and suspension of ontology in body-mind dualism and rationalist virtue controversy. Drawing on the work of Bhaskar, Segal and Slote, a renegotiated and more meaningful sense of transformation emerges from their cumulative analytical and conceptual enrichment. In the complexity of possible relations between self, self-concept and society, lies the traditionally neglected transformative middle of sui-generis human depth. In redress, arguably, Bhaskar's meta-philosophy accommodates Segal's experiential depth analysis and Slote's understanding of empathy and receptivity as valuable insights for 'awakening' to transformative process.

\section{Introduction and context}

In the academy, growing acknowledgement of and value for transformation features in the gamut of contemporary epistemology of the human sciences. Notions of transformation seem intertwined with questions of ontology and consciousness: "The nature of the self is intimately connected to all normative enterprises that engage the issue of transformation (morality, education, religion, therapy, social development, political and economic theory and revolution)' (Segal 1991:56). The relationship between ontology (being) and consciousness is a salient feature in Bhaskar's deep ontology; Segal's consciousness of self or self-alienation. Whilst conscious recognition and empathy for real beings is conditional for Slote's virtue of receptivity, there seems little choice for these authors but to emphasise being as conscious and consciousness as an emergence of being in transformation. Clearly a non-reductionist, non-normative approach is evident.

Institutional (normative) occupation with transformation has had a transforming effect (despite resistance and marginalisation) on academic and other social institutions. Some may claim transformation is the new (emergent non-normative) development (Joas 2000:73-76; Therborn 2000:49-72). Yet, much is to do with best-practice policies and a better, virtuous, manner. Baker and Potterton's handbook (2014) for discipline in catholic schools promises much for education in the South African context. One is reminded that the ideal of transformation is a core constitutional and legal value enacting the transformation of South African society. Interesting and very unphilosophical interventions happened: Constitutional theory transformed legal practice, bringing into being choices made by real people driven by needs and wants, an issue which divides Bhaskar (2002a:12-13; Bhaskar \& Norrie 1998:565) and Segal (1991:19, 118-119), nevertheless a case where democratic values became fact. Yet, just as anti-dualist intention transcended dichotomy, it did so imperfectly. South African society and the world are deeply wounded by gaps between theory and practice. Notwithstanding this state of affairs, everyday people wake up to lives filled with transformative agency in ways we barely notice, naturally and smoothly. How does such multi-layered transformative complexity happen and what are the philosophical signs? Bhaskar's 'transcendence' vindicates a ubiquitous transformative agency, whist Segal (1991:118) agrees - 'Rather than finding agency only in rare cases we find it potentially all round us, in everything we do ...'

\section{Grounding questions}

Of particular interest in this investigation is where or how our philosophers here ground their arguments for transformation, agency and virtue. The relationship between organic development, the way of things growing into fullness and moments of will and thought which characterise intentional agency, the consciously participative aspects of self in transformation, is intimate: The former, often providing naturalistic metaphor (Haught 2009:284-314; Hewlett 
2009:159-172; Runciman 2000:307-314; Scott 2009:173-197) for the latter, but challenged by paradigms of 'society as open and discontinuous' (Schelke \& Krauth 2000:1-29). A reclaimed naturalistic sympathy is evident in Bhaskar, Segal and Slote: Bhaskar ([1979] 1998) actively conceives of the limits of naturalist explanation amidst nature-phobic debate in sociology and hermeneutics. Much rides on nonreductive science and conceptions of society as open-systems. Segal is perhaps most open to a reduction to complexity. Slote is adamant that receptivity to nature and self-nature is the virtuous touchstone required. What inspires the intimate work of transformative praxis: Aiding and abetting the revolutionary work of the practitioner, therapist or spiritual companion, is the return to a non-reductive, non-dualistic, enchanted encounter with real complex beings, with open futures.

All this must be viewed against a philosophical back drop where any expectation of neat theory-building had been thwarted by traditionally described body-mind dualism (Bhaskar [1979] 1998:98; Van Gulick 2009:40-73). Recent efforts to reach re-conceptualisation of old debates through theories of emergence (Murphy \& Stoeger 2009) suggests limited (Archer 1998:xvii; Bhaskar [1979] 1998:3, 20, 53, 82-83) naturalistic possibilities for non-reductive (Gregerson 2009:284-314; Howard 2009:141-157; Murphy 2009:19-39) renegotiation, whilst providing opportunity for Bhaskar and (to some extent) Segal, to explore and explain intentional and moral agency. It is these moral, existential and spiritual aspects of transformation which receive focus here, but not in a way that is disconnected from 'entire society'. Transformation needs theory and is very much about giving us something to do and reflect on, amidst wide epistemological understanding.

Perhaps, considering current interests, a useful contextual place to begin is the insight from Mezirow's understanding of 'transformative learning' as 'perspective transformation'. He reports on research:

Findings suggested a generic development in which maturity in childhood is understood as a formative process that includes assimilation of beliefs concerning oneself and the world, including socialization and learning adult roles. Adulthood was perceived as a transformative process 'involving alienation from those roles, reframing new perspectives, and reengaging life with greater degree of self-determination.' The process was characterised as 'a praxis, a dialectic in which understanding and action interact to produce an altered state of being'. (Mezirow 2000:ix-xi)

One can predict similar descriptions of transformation in a number of mystical writings. However, Mezirow provides a neat theoretical start for our examination of Bhaskar, Segal and Slote by linking the traditionally dualist concepts of theory and praxis. In the transformative realm of spiritual practice, overcoming internal and purely self-referent distinctions and dualism is a necessity for Bhaskar. For our flourishing, the analysis extends outward to science and society. Slote would claim that receptivity dissolves dualities and that holding onto distinction and duality is not very useful for getting along in this world. Segal's explication of self-referent experiences of alienness shows us how deep-seated distinctions produce self. For some, this begs upheaval in transformative acts and integrations necessary for the emergence of non-dual consciousness. The agenda here is anti-dualist.

\section{Anti-dualism}

From ethical consideration, theory and practice of transformation faces the challenge of overcoming philosophical reduction, dualism and dichotomy, socially alienating practices and split concepts of self they engender (Schreiber in press; Segal 1991:141). There seems a natural fit for 'transformation-speak' in meta-inclusive, neo-integralist world-views. In this context the philosophical resonance of transformation, with bed-fellows ontology and agency, traditionally mishandled and neglected in philosophy and religion (Bhaskar's opus; De Villiers 2006:102; Kourie 2009:167; Schreiber in press; Segal 1991:3, 10), has fresh airing away from suffocating reduction and heteronomy.

Transformation is much engaged with 'subversive' (Benedikter \& Molz 2012:51) and 'heretical' (Berger 1979) anti-dualist fellow travellers in critique of modernist consciousness, prompting Bhaskar and Hartwig (2012:187202) to push beyond 'East and West' to pose a theory of non-dual grounds states in which the necessary conditions of life, consciousness, rational judgement and ontic agency (as conditions for transformation) are enfolded, and from which new ideas and things emerge. In the most real possible sense, transformation emerges in beings because it is embedded in non-dual creation.

When non-dual states meet duality, transformative possibility is excited. Becoming 'non-dual beings in a world of duality' (Bhaskar 2002a:10-11) is given some philosophical (and experiential) significance or imperative for practical mysticism, learning, transformations, awakenings (Bhaskar 2002a:183-184; 2002b:xx-xxviii) and all moments of the emergence of mind (Brown 2009:198-226). In comment, one feels non-dual states to be unitive rather than distinctive and that unitive perspectives would view many self-referent distinctions as unsustainable personal prejudices.

Our 'awakening' is, so Bhaskar (with Segal's support) claims, irreducible, creative, spontaneous, direct or immediate. So much textbook wisdom ignores the function of play in spiritual transformation. If transformative awakenings are moments in the emergence of mind, mind has transformative potential but has no form before that moment of emergence. Narrow expectation is sure to fail. Mind and phenomenology of empathy/love, (Bhaskar 2002b:ix-xi, 91-166, 172-232, 313-364, 2012:165-182; Slote 2007, 2013) are grounded in co-presence of enveloped ground-states or fine interiors of being. The analysis is sympathetic to a limited naturalism, relatively enduring social reality and the role of reflexivity. 


\section{Bridging questions}

We have already suggested Bhaskar's, Segal's and Slote's sympathy or naturalistic availability. But what about social vulnerability and the bridging questions? Slote, at first, seems to suggest a naturalist reduction: The experience of warmth in the neonate whose moral flowering, in empathic caring and receptivity is a sign of virtuous transformation and advancement and building of moral character. Slote begs nature/nurture unity in the primal experience of empathy, open to the social role of Hoffman's inductive discipline in empathic learning (Slote 2013:9-10, 38, 86-87, 113-115, 124, 197, 219). This philosopher's reliance on Hoffman suggests however, a complex interior relationship between warmth and acceptance and Hoffman's guilt. Implication for experiences of alienness follows. Slote's sentimentalist but not irrationalist analysis, from the ethics of Care (Slote 2013:i-xii) and primarily focussed on the passive components of empathy (hence his virtue of receptivity), finds grounding in the Jungian concept of the collective unconscious: Serendipitously, it is that theoretic level of consciousness from which many archetypes and symbols of transformation arise in dreams and cultures. The analysis may benefit greatly from a reading of Bhaskar's co-presence of ground-states in creation.

Segal (1991:ix, 87-99) proposes a 'presence theory of agency', grounding 'agency' and alienating principles in self (1991:129), via 'activity molecules' and indirect perceptual integration' (pp. 28, 35-37), treating 'agency as the presence of the self within one's activity' (pp. $x, 28$ ), in an attempt to overcome practice-theory split. Here too, Segal's anti-dualist critique $(1991: 54,104)$ may benefit from Bhaskar's notion of transcendental acts (Bhaskar 2002a:10, 2002b:xviii, 2012:35-38, 125, 131-133, 145-148, 165-182; Schreiber in press). In turn Segal adds beautiful experiential colour and analytic detail to the former.

The experience of alienness or dissonance as a way of experiencing the self is a useful existential deepening and extension of Bhaskar's reflexive response to social and scientific absences and deficiencies. In this way it is perhaps possible to read Segal's (1991:27) integrated unity of relations between self, self-concept and 'self and the activity', conceivably grounded on non-duality as a potential within ground-state envelopment, but integrated in personality through the experience of dissonance (dualism), which it must then overcome or transcend before it is said to be 'integrated'. It is this experience of alienness, within a 'structured web of agency' (Segal 1991:9), in which notions of causality (pp. 16, 25), norms of reason (pp. 70-71), personality types and cultural systems must feature and inter-penetrate (Luhmann 2013:x, 196-197), not to mention phases of life, all of which are instrumental in changes of self-concept and integration (Segal 1991:x, 49). The social aspects of being receive very serious treatment. They are complex and speak of what being in the world is like, the ontic pre-occupation.

\section{Ontic turn}

The three 'analytics' here share sympathy for naturalism and the instinct that overcoming dualism requires investigation into depths of being and, to some extent, an attitude of realism about their targets. They are much concerned with the business of categorical and conceptual enrichment. Their critiques are post-modern (in the contrary sense), and in common seek a negotiation between reason and emotion in the existence of multi-dimensional 'whole lives', which participate in the production, re-production and transformation of the human matrix (Bhaskar 1993:223-366, 2012:127-129, 218-219; Schreiber in press). To the degree that these philosophers evidence ontic turn, they join a growing interdisciplinary array. As Segal (1991:83) notes, the 'common intellectual thread [to these approaches] ... is the notion of unity, coherence, integrity or wholeness'. Segal (1991) states:

While it is unusual to find an explicit formulation of these attitudes, they may be eked out of views on education, mental health, moral ideals, responsibility, self-transformation, authenticity, and so forth. (p. 83)

Bhaskar's critical realism may be described as radical/deepontology, providing critical re-conceptualisation of the relationship between theory and practice (Bhaskar ([1979] 1998:87, 97-99) and the fact-value distinction, in order to re-vindicate reflexive/rational judgement (Bhaskar 1980:16, 1993:214). The philosophy of meta-Reality represents a 'spiritual turn' in which transformation and moral agency are set in an ontic totalisation of love and non-dual consciousness. Re-theorising (in post-Habermasian sense?) transformation and agency, Bhaskar (2012:xxiii, 129-131, 218) re-situates spirituality as a philosophical and ontological good in an 'emancipatory' (sic) axiology.

It seems an obvious matter of rational judgement (at least for realists) that transformation has some sort of rightful (evaluative) priority in Spiritual meta-theory. Knowledge is dualistic and relative, agreed: As describable product it is always in the past and yet it looks to the future emergence of concepts and realities we want and need. Between these two poles of knowledge is a rather under-described process of the transformative present in Bhaskar, for Segal presence, and for Slote empathy/receptivity. How might these inform a theory of personal transformation in a world of social relations?

\section{Social theory}

Though Slote's receptivity has consequences for relations, Segal explores self-experience in social relations, whilst Bhaskar is also interested in the relationship between society and its theory. For him, social theory advances after the fact of the transformation of its own society which it then describes. However it must be said, just as the social dependence of social theory is established, society itself cannot be conceptualised apart from some theory, be it proto-scientific, scientific or ideological. Theory informs practice. 
Conceptions of transformation therefore depend greatly on the values most prized in oneself and one's (shared?) view of the world. For Segal (1991:77, 91, 100) values, valueembedded emotions and self-ascriptive beliefs (p. 168) raise the status of 'self-concept' in regulating or appropriating transformative values (p. 78). The possibility of self-deception and false expectations being present raises the question of self-scrutiny, self-transformation, change and what it is to be fully present to such exercise. Policies and descriptions of transformation are irrelevant without committed people willing to be transformed by a reflexive implementation.

Being receptive to such implementation acknowledges the irritation, discomfort of temporary marginalisation and losses in self-concept in the process of adaption. Whatever theoretical position one takes (hopefully, honouring demands of unity, integrity or wholeness on the part of society and the person), some coherent description of incoherence, contradiction and dialectical absences (Bhaskar 1993:6-7) and of things falling apart are required to understand the threads or relations of social functioning and why these sometimes fail.

\section{Relational society}

Bhaskar suggests: Societies are naturally self-transforming, open-systems (a highly problematic notion) in which anything can happen. Put simply, transformation is unpredictable: Absolutely, in the sense that after all effort, no transformation may happen and relatively, in unpredictable shapes and forms of transformation which may emerge. Transformation might be experienced negatively. Slote (2013) suggests:

$[W]$ e have seen that the virtue of receptivity in one of its aspects involves accepting the large amount of accidentality and unpredictability that characterize both normal and notso-normal human lives. And the insistence on life planning and the (greater) control over one's life it is supposed to bring one therefore also constitutes an unwillingness or failure to see the potential or actual satisfactoriness of ordinary human lives as we typically lead them ... [I]f we accept human lives as potentially and often, actually, satisfactory, then we in some sense have a receptive attitude to Life (with a big $L$ ) itself. (pp. 231-234)

Social life is the meaningful 'background of beingness' (Luhmann 2013:163) and naturally 'enchanted' for Bhaskar, because transformation is inextricable from the fact of social life. Transformation as ground-state for all activity emerges in society through agency. Society is the mediated transformation game, giving dualistic face to non-dual transformative potential. Internal distinctions become external expectations employing dualism. This might partially explain why the more subtle aspects of transformation apart from revolutions and dramatic recovery from addictions, are often opaque.

However, for Bhaskar, in agreement with Segal, 'why' societies and persons transform, is because they share a set of structural and relatively enduring relations, which mediate transformation. These are, amongst others: internal and external, social, psychological and material, covering a gamut of social and logical agreements, contracts, structures, attitudes, thoughts, beliefs and conventions. These are then mediated by the offices and positions people take up:

Thus people in their social activity must perform a double function: they must not only make social products but make the conditions of their making, that is, produce (or to a greater or lesser extent) transform the structures governing their substantive activities of production. (Bhaskar 1989:78)

To have effect, relations must be mediated. The mediations, according to Bhaskar ([1979] 1998), are occupied by people,

their positions, places, functions, rules, tasks, duties, rights, etc. ... filled, assumed, enacted by individuals, and of the practices ... in which, in virtue of their occupancy of these positions ... they engage ... such positions and practices, if they are to be individuated at all, can only be done so relationally. (p. 41)

We are not only appointed to positions, we grow into and with them.

Slote's (2013:212-214) contribution and colouring of relationality rests on the awareness that: 'Receptivity' thus not only stands in contrast with both passivity [understood as 'without any ... potential for ... responsiveness'] and activity, but helps us understand why passivity is not a value and why or to what extent activity is one (Slote 2013:214).

However, the reality of a relational society means:

Sheer or total activity or activeness isn't really a virtue because it is inconsistent with so much we need and want in our lives: with intellectual openness, with love, with relationships, with caring, with moral thought, with ... virtue and happiness. (Slote 2013:214)

Furthermore, 'we have seen that receptivity of an epistemologically non-rational and at least partly irrational kind is essential to valuable relationships and feelings towards others'. How real, and in what way, is society?

\section{Social realism}

These ingredients of society for Bhaskar ([1979] 1998:25-43) and for Segal $(1991: 5,141)$ are real causes open to description in coherent social ontology or 'social cube', that is: Our material transactions with nature; inter-personal relations (both important to Slote); attitudes towards social structures, institutions and cultural items, and the choices we make in producing, reproducing and transforming them. In addition, one might add ... the option of abandoning or refusing them, and intra-subjective engagement with interior stratifications and structures of consciousness and personality. These together mediate our concerns, providing the contoured landscape of relationships we find meaningful, but also the social targets of meaningful transformation which are meaningful in themselves (Bhaskar 2002b:xxxvii), and this is why they contribute to meaning-'making'. It is these 
relational dimensions that we experience as alternatively 'broken' or 'incomplete'. The analysis does not rob society of its great mystery, but deflates much of the overwhelming difficulty that often complicates social theory.

Relations for Bhaskar become for us real (however limited by their relative endurance) objects of knowledge in the multi-/inter-disciplinary matrix. They describe or prescribe the limited available field in which we act as real transformative agents in a real world. Underlying the argument is an intuition that the dichotomy between theory and praxis no longer stands, since they share similar (but stratified) 'objects and targets in all rational activity' (Bhaskar [1979] 1998:25-43).

Bhaskarian 'reason' is important to correct the moral lacuna and absence of empathy of keen interest to Slote and to which Bhaskar ([1979] 1998:86) gives Marxian twist. Paralleling Segal's (1991:203-251) interest, in a contemporary holist sense, this cannot exclude emotive content - Bhaskar cannot be accused of Faustianism (Slote 2013:xi, 4). It can however be said of this Trio, that they attempt 'to provide the individual with a sense of integrity in a context that is deeply problematic and a breeding ground of self- deception' (Segal 1991:xi).

Bhaskar's structural approach to society (supported by Segal), describes mechanisms that are of relative endurance, but which nevertheless are transfactual or causative in contradictory phenomena, making society 'quintessentially mutable' (Archer 1998:196). Preconceptions about the ordering of society and its transformation, either synchronically or diachronically are avoided. Social realism in this way is non-prescriptive and non-normative. Explanation therefore must have something of an analytical history of society's emergence. One might say of transformation that it is best noted over time and in the context of a life work of integration, for Segal and arguably so for Bhaskar and Slote. However, even a lifetime of transformation can be reversed under certain circumstances.

One suspects it is in the fundamental openness of relational possibility that frightens many. So often people take up influential positions without the necessary attitude of openness such a reality warrants. Rather what we see more of is a narcissistic growth in the domain of personal control in corporate and other aspects of life.

\section{Not individuals, not society}

Of significance is a common understanding amongst the authors mentioned here, that transformational theory requires a critique of individualism including types of atomism and monism deployed in an epistemology of scientific individualism. In response, Bhaskar and Segal plumb for a complexity theory of persons/agents/transformation. Segal claims: Actions are not seen as the making happen of individual moments, in parallel with Bhaskar's ([1975] 2008:xiv, 221-222) critique of Hume's empiricism. Both Slote and Bhaskar also critique the Faustian/modernist rugged individualist existence as an aberration. In similar vein, Bhaskar ([1979] 1998:28; Archer 1998:190) observes that 'the predicates designating properties special to persons all presuppose a social context for their employment'.

\section{Mediated society}

People as individuals do not create social relations, but rather, these relations act as pre-existing conditions for peoples' activity. Society is an open ensemble of structures, practices and conventions which individuals reproduce or transform and often for existential and moral reasons (Bhaskar ([1979] 1998:36-37). More importantly, transformation accommodates the experience of alienness and reflexivity. This position, Bhaskar ([1979] 1998) claims, avoids the classical positions of the Durkheim/Weber debate:

Society, then, provides necessary conditions for intentional human action, and intentional human action is a necessary condition for it. Society is only present in human action, but human action always expresses and utilises some or other social form. Neither can, however be identified with, reduced to, explained in terms of, or reconstructed from the other; there is an ontological hiatus between society and people, as well as a mode of connection (viz. transformation) that the other models typically ignore. (pp. 36-37)

Social forms are necessary and conditional for any intentional action because they possess a characteristically ideological component which gives those social forms their coercive power. Yet coercion cannot be said to determine and therefore cannot explain transformations. Much rides on notions of legitimacy (Hassoun 2014:119-134). Clearly, descriptions of power-relations do not predict transformative outcomes and permit no coercive reduction. So too for autonomy and freedom. Slote believes that transformation is best effected when the cold face of coercion is replaced by empathy. 'What then', one asks, 'are our freedoms'?

\section{Autonomy}

It is clear to Bhaskar and Segal, that relations, while constituting structures, are not themselves adequate in the agent to transform those structures. They are an important but not the final frontier. Agents are freer than the structures that precede them. In other words, transformation is effected by the causal placement or situation between positions people hold and the activities (including mental ones) their so doing enact. Limitations and responsibilities are real and cannot be sundered. The moral lesson is that multiplication of dualism hardly ever makes things right.

For Bhaskar and Segal, but of greater priority for Slote (2013:217-219), it is necessary to balance notions of autonomy by recognising its limits and to counterbalance its modernist privilege. 'Perhaps', Slote wonders, 'receptivity and autonomy are ... co-equal virtues?' Because being uncritically receptive of patriarchy, for instance, can be disastrous. Nevertheless, we are reminded that a certain distance is existent in the psychological experience, providing some autonomy from social realms, and in which 
receptivity remains a choice. 'Thus we do not suppose that the reason why the garbage is collected is necessarily the garbage collector's reason for collecting it (though it depends on the latter)' (Bhaskar 1989:80). Personal discernment might indicate the place we are most free to change, but what is this personal discernment without its relations to reality?

Bhaskar's argument for balanced autonomy is also addressed to hard linguisticism and historicism, accepting their mediational status of transformation, but permitting no predictive reduction to them. Though we make neither language nor history, these are nevertheless totally dependent on people's utterances and unpredictable intention which resides in a psychological space which gives us some ontic autonomy and freedom from society, history and language conventions. Bhaskar ([1979] 1998:37-48) claims: 'a radical transformation in our idea of a non-alienating society'. For this can now no longer be conceived as the immaculate product of unconditioned ('responsible') human decisions, free from the constraints (but presumably not the opportunities) inherited from its past and imposed by its environment. Limits to autonomy are important to theorise, because each one of us is subject to some moral education in the primary formative environment of family and culture. These however do not always carry predictive power over moral outcomes in the individual.

It is clear that for Bhaskar and for Segal (1991:99-111), neither individuals nor society, but a structural web of agency, arising out of a constellation of wants, beliefs, attitudes, evaluative judgements and emotions in which receptivity plays a part, is what best describes the 'connectedness between self and activity, that has no particular specification', yet conceives of 'direct and active presence of the self within the activity performance', wholly engaged.

It is herein, the act of agency, that Bhaskar and Segal are most similar, able to theorise phenomena such as mental dualism and distanciation, split intention, ambivalence and self-conflict and also the immediacy of agentive experience in spontaneity, creativity, empathy and so forth. For Segal it is in such activity that the self emerges as immediate presence and 'what gives us the sharpest sense of the activity of the self'. Properly, transformational acts seem to operate best without expectation, but through 'letting-go' or release of self-control (in agreement with Slote), in transcendent activity, 'being one with' another or in a task, or teamwork in which the self and transformation is permitted to emerge spontaneously. The planned strategies for transformation, our approaches, and negotiations must be receptive to relational processes and uncertain futures. Spiritual friendships and reflexive communities are important but, hard normative expectation necessarily fails.

Thus it is philosophically imperative to explain and criticise ideology, science and religious ascription by exposing fallacious value relations (including certain claims to be valuefree): 'For beliefs, whether about society or nature, are clearly social objects'. Superior explanation or conceptual criticism then engages in social criticism and sets up the conditions for change: 'theory fuses into practice as facts about values, mediated by theories about facts, and transformed into values about facts'. The non-sense of value independence in social science collapses because whatever value so held can be proven to be false. Values are reasons and reasons are real causes of agency for Bhaskar ([1979] 1998:87). Very often transformation requires the shedding of false values, an evaluative but necessary judgement.

\section{From materialism to agency}

Upon the success of proving from analytic perspective that (contra Hume) emotions can be 'reasons' and these can be 'causes', accompanied by answers to traditional objections (Bhaskar 1993:63, [1979] 1998:83-93); Bhaskar ([1979] 1998:125) builds his theory of people and intentional agency called 'synchronic emergent powers materialism' which proposes and describes the ontological depth of agents in contemporary terms.

\section{Depths and absences}

Commitment to stratification or the dimensions of being in post-Freudian tradition means a rejection of purely superficial data. Instead of relying on horizontal explanations of transformative experience, Bhaskar suggests the fact that conditions and antecedents are present implies a vertical explanation of generative mechanisms which give ontological depth to social temporality. These factors then explain the depth of 'the present'. If society is constituted in meaning and transformation, society's absences are equally meaningful.

'Depth-work' implicit in all three theorists here, reflects Bhaskar's assertion for its universal validity in science and conscious flourishing. Absence and negativity are important, because an absence (moral or material) becomes the ground or setting for imagining, searching or transforming towards the desired totality. Without the possibility of moving from an 'is' to an 'ought', transformation seems virtually impossible and denies us the non-dual ground of transformative human praxis. Transformative praxis (filling absences) produces science, new concepts and theories, social betterment and emancipation, invigorating moral and spiritual dimensions, and proceeding from real ground-states of non-duality, love, creativity, spontaneity and so forth; hence the value in practice of discernment.

In compliment, Slote thinks on the passive aspects of receptivity as being a moral touchstone within the ontological experience of the collective unconscious, and Bhaskar might argue that all virtuous and moral traditions have causal, mediational and conditioning effect on transformation.

\section{Slote's receptivity}

Virtue theorists like Slote are formed and transformed in one of Western philosophy's oldest traditions, consistently (but not without hiatus) reflected in religious pre-occupation. At 
the core of the tradition is the concept of rational judgement, so necessary for Aristotle to describe the 'good life'. 'Enlightenment' and 'Faustian' aspects in advancement, and privilege of 'reason' in recent centuries of normative studies, have more latterly received sentimentalist attention. Slote (2013:216-217) claims this critical trend is directly consequential upon the rise of 'care ethics' (which analysis Slote wishes to extrapolate and exceed), evidence of the incomplete 'holistic turn' within the medical paradigm.

Of critical interest to Slote (2013:210-211) is how the rationalist tradition has come to marginalise emotion, nature and women, ignore receptivity as "a kind of virtue' and as a 'character trait', by preaching the myth of control and dominance, complete with Aristotelian notions of 'more activity is better' and combining in a pervasive 'rationalistic mind-set' in ethics tradition.

For Slote (2013), as the virtue 'that dares not speak its name', receptivity is the

background 'haunting' of ... environmental ethics and psychologists' and philosophers' description of how empathy works. Whenever the green thinker deplores our dominating, controlling, or highly activistic attitudes and actions toward the environment, they clearly think we should be acting and thinking differently, and even if and when the term receptive isn't mentioned ... that term fits or would fit the stance vis-a-vis the environment. (p. 210)

Perhaps, most promising in Slote's observation, is the phrase 'acting and thinking differently'. Such implies the possibility of some mental movement to alternatives - Like that from 'is's' to better (evaluative) 'is's' or to 'oughts'.

\section{From 'reason' to empathic reflexivity}

The reflexive aspects of transformation: Thoughts about thoughts and thoughts about those; attitudes to attitudes; feelings about feelings (important to Bhaskar and Segal), and so on speak of being conscious about being conscious! We are free to examine our chosen relations to structural mediations. Participation in a critique of consciousness is imperative, analysis is important for integration and perhaps coping with loss of former self-referent meanings. For Segal the experience of alienness is seminal to this self-examination. In Bhaskar, such introspection is necessary to develop rational judgement and establish what the proper objects of our moral choices and transformations, loves and attachments are. Needs and wants are sometimes either confused or in some or another way misconceived. Slote reminds us that, in that moment of discernment, to begin with an attitude of receptivity to oneself and to society, which (to my mind) is very often the gain of maturity and integration.

Slote (2013:211-219) intends to overturn: 'Enlightenment insistence on rationalistic foundations'; Faustian notions of perfectionism, 'of living according to a life plan' and 'the liberal imperative to critically scrutinize every aspect of our life, [that is] about controlling and dominating over nature, and about the quintessentially preferred rationalist notion of autonomy'. 'More strongly', Slote thinks, 'receptivity actually functions as a kind of touchstone for other values ... to be placed at the very centre of things', consistent with 'being willing and able to think and decide things for oneself', but limiting exaggerated Kantian notions of 'sheer "independent minded" response', which 'isn't the basis of our normative obligations'.

Clearly, receptivity anticipates a reflexive response which is 'more than willing' to be active and change if needs be. Receptivity does not over-arch, supervene or possess hierarchical privilege in relation to 'whole of virtue and that it is often best co-mingled with or limited by elements of activeness', whilst requiring 'action that grows out of receptivity'. A 'proper appreciation of [activity] ... also tells us that there are and have to be very substantial limits to the value we place on being active' and 'contrary to Faustian and Enlightenment ideas about what is good ... in human life, receptivity plays a role in some of the most important aspects or parts of our lives and is properly viewed as a virtue'. It would appear that Slote's permits a deeply contemplative view.

If it is permissible, necessary or even meaningful to read Slote 'into' Bhaskar and Segal, or read Bhaskar 'under' Segal and Slote (in conceptual support) as earlier indicated, it is so because collectively they conceive of experiential depths in active and passive aspects of being and transformation and how it is that passive aspects emerge in activity, science and society. For instance, ground-state receptivity and organic receptivity (in eye, ear, nose and brain, etc.) can be read 'under' receptivity's practice, social attitude and so forth, this is in parallel with Slote's focus on the passive aspects of receptivity as 'trait'. Of further note, Bhaskar's reflexivity retains the rational-emotional balance that Slote wants and extrapolates. What drives receptivity is in some parts a Segalian experience of presence and sometimes in a negative or alienated false presence, in a real Bhaskarian agent.

We may take note of the discernible philosophical movement from (modernist) reason to (more complex) 'e-motivated', empathically reflexive being. This is Bhaskar's intent: To pose a meta-philosophy ultimately receptive to more substantive theory building whilst thinking on the conditions for their emergence. The stuff of contemplative discernment seems to be at large in the world of philosophy as indeed philosophy, is at large in the world.

\section{Conclusion}

When receptive to things and thoughts, Slote opines we are more that empathetic and open-hearted. However such openness (empathy) is the necessary condition for receptivity. Being receptive, we might be said to be a step more engaged. More than willing to be so, we suffer no split intention, we feel at one with the other in 
non-alienating and non-dual ways of response. Bhaskar adds, we are able to read meaning, transformation and spirituality into the structures of society because these are the fine interiors of real beings, meaningfully encountered only insofar as they are real. Thus it is that they have engaged our empathy, receptivity and so on, in more than light hearted fashion. Bhaskar (2002b) has it we need to understand perception

as immediately non-dual identification of the world, as meaningful, valuable etc. we need to critique the philosophy of modernity, which generated a thesis of dis-enchantment ... so that we have the immediate identity of being and meaning, reality becomes meaningful ... [in converse] we have the displacement of meaning, signification onto reality itself so that things in the world mean things and are constituted semiotically and interpreted hermeneutically in a multiplicity of ways. The world becomes a meaningful text. (p. xxxvii)

Receptivity is in this sense the necessary and conditional attitude for an 'awakening' to Reality - The Other, the Open: Truth and being as (alethically) knowable presence. Meaningful acts of interpretation cannot, if they are to succeed, proceed from cynicism. Some things are felt and known in the very act of receptivity, that is, directly!

Few would deny the irreducible, spontaneous, creative and immediate effect of ('well placed') humour, in inspiring warm-hearted generosity. Nor are we unfamiliar with the immediate expanse of warmth generated by the belly laugh. The suggestion is that awakenings are more than rational events. Cognitive engagement (receptivity) understands the humour in some rational way in order to have this upset by the dangerous punch line. Awakenings disrupt. This is transformation by cutting through the normal face of things to a deeper sense of how things are in the world. However, neither puncti-form moments, nor their linear sets, are enough to predict anything. In this limited sense we are required to develop our own critical sense of humour. Participation requires a constant and unpredictable reorientation away from face-saving illusion, into a reality that is truly open, opportune and mysterious.

Particularly Bhaskar and Slote wish to deliver us to an appreciation of the complexity, magnitude and depth of reality's enchanted satisfactoriness in which we have a more expanded sense of the negotiable. Whilst the reflection here is formal, follows a certain way of working things out with logical tools and so on, there is a vocative realism which these philosophers wish to expose in the ground relationship between selves and environments. For these authors it would appear that transformation reflects a growing sense of our selves, whose needs and wants and other agentive intentions are to be embraced for revitalisation of the spirit, in moving towards a more congruent reflection of mysterious reality. There is nothing to fear in this; transformation happens with or without us. But what sort of depleted life does not wish things to be a little different? This is the way of a nonsubtracting (and therefore extending) Spirituality: Open to post-secular, secular, holist and anthropological approach
(Schreiber in press). Final meanings and ultimate concerns are socially embedded in the penultimate and dualistic world. Perhaps this is an awakening?

In an indeterminate axiology, transformation requires reflexive refinement in moments of self-examination and the flourishing of relations, through definite competencies of well appointed, emotional and spiritual intelligence. Our authors provide some clues of what these operational traits and skills might entail and what depths of analysis, spiritual enquiry and self-knowledge are available in this context. Some will take insights seriously, partially or not at all. However if we have some little mind-map or depth analysis with which to wipe back the grimy veneer of powerlessness and expose transformational reality from within, beyond our stories, symbols and archetypes and so transforming them, we also purchase some orientation for our practical wisdom, a concept of manageable targets, even if we have no certainty about the result of our intentions, but that they are still reasons and causes in practice. Reality is that more complex mystery which beckons a transformative response, a fusion of theory and practice. The reading of science perhaps requires updated tuning to ancient resonances.

Transformation, reflexivity and receptivity are sui-generis aspects of being and are so in various places in society. They are inalienable, exhibiting a creative net or core, entirely alienable from 'high maintenance' ego-strategies of control and self-misconception. It would be apparent that integration requires some adjustment to more sustainable relations - upheaval, stimulus, irritation or revolution may play a role, as might a communal barbecue. Reflexivity as an aspect of the self-observing observer, the soft interior and suigeneris non-dual mirror of being, reveals itself in the critical and intelligent act of exposing and melting internal conflict, self-alienation, incoherencies and self-illusion in an interior dialectic that is neither painless nor alienable in others. This is the point of Bhaskar's reflexivity, Segal's self-alienness and incoherence, and Slote's insistence on receptivity.

Self-referent elements of meaning are apparent everywhere. Meaning cannot be extracted from the meaningful! Rather, meaning remains the ever-more complex, universal, receptive and challenging background of being, in which we share as meaningful beings. This then is the reality which should move us to seek a totalising slow embrace in transformation, for our flourishing, empowerment of being and consciousness. In contradiction of Humean excess, practical transformation cannot but implicate itself in a move from conceptions of 'is' to an 'ought'. How else might 'oughts' become 'is's'? In a very real sense Hume may have unintentionally tabooed our 'first and last freedom' to think spiritually.

From a strange collection of philosophers who have attempted and breached the theory-practice divide quite successfully, it might be expected that an easy enumeration of practical insights would be possible. It is not. The conceptual enrichment is intended to provide just that. Its application in a plurality of open possibilities must be 
encountered in the exercise which philosophy here intends to empower. Transformation is real and inalienable, whilst enumeration raises unwarranted and normative expectation. Transformation clearly speaks a different, perhaps intuitive language: The language of being rather than that of 'simulacra'.

Perhaps most significantly, this small investigation reveals a contemporary, shared commentary on the decentring capacity in aspects of self, beyond and transgressing superficial self-concept. In vitally transformative acts it is; the 'letting go' of self and self-concept, shedding self-preoccupations, which is the most meaningful activity of the observing self. Transformation requires not only an outward embrace of reality but an inward orientation towards the depths of being and being conscious. The learning is not preached, but appropriated in myriad reality. Empowered people, sometimes through a philosophical method, are so, with a greater sense of sustainability, able to de-centre themselves most intelligently and with minimal fuss - questions of identity are less fragile, more permeable perhaps. The intuition being, that it is incumbent upon resilient existence that decentring of the self is directly linked (perhaps not absolutely) to universal flourishing. Into every life a drop of un-begrudged martyrdom must fall, or so it seems. Though the conception is not theological, the resonance of kenosis, its traditional mystical ties with transformation find some analytical alliance!

No doubt philosophically, psychologically, spiritually and politically speaking, it is meaningful to have a refreshed picture of our relatedness in the cosmic dimensions of being. Illumination is truly immanent, but in what best useful way, one cannot predict, but we here merely offer a philosophical awakening, an altered perception from which to proceed with the more nubby features of practice. In such a theoretical investigation it is hoped that practice must be informed. This reflection certainly indicates a will to purchase reconciliation and some integration of meaning and reality in a profoundly 'transformative turn'. If in the end our appreciation of an ultimately mysterious but valuable totality is enriched and life enhanced, we have a good result.

If the under-labouring of three beautiful minds leaves a tingle, it leaves a deep and resounding resonance. We are ontologically, socially, and asymmetrically situated (although realistically limited in our plural reflexive responses) in a transformative world. The insights here gathered inform, empower convincing appropriation. It seems they enact a mature enchantment, against distinctions and dualisms of youthful expectation and traditional conceptions of why thinking differently is impossible. Profoundly, the philosophical contribution undoes much self-confusion.

Perhaps our sojourn delivers us to a boundary experience, because a more generous acceptance of mystery (which is reality) and which calls or summonses without preconception, is where mysticism and science may join, to refuse tyranny and petty self-referent distinctions along with their various ideologically entrenched 'hurrahs'. It also indicates some foundational progress in a contemporary philosophy of practical mysticism.

\section{Acknowledgements Competing interests}

The author declares that he has no financial or personal relationships which may have inappropriately influenced him in writing this article.

\section{References}

Archer, M., 1998, 'Realism in the social sciences', in M. Archer, R. Bhaskar, A. Collier, T. Lawson, \& A. Norrie (eds.), Critical realism: Essential readings, pp.189-205, Routledge, London.

Baker, A. \& Potterton, M., 2014, Fairness for all: Doing discipline differently, Catholic Institute of Education, Johannesburg.

Benedikter, R. \& Molz, M., 2012, 'The rise of neo-integrative worldviews: Towards a rational spirituality for the coming planetary civilization?', in M. Hartwig \& J. Morgan (eds.), Critical realism and spirituality, pp. 29-74, Routledge, Oxon.

Berger, P., 1979, Heretical imperative, Anchor Doubleday, Garden City, NY.

Bhaskar, R., [1975] 2008, A realist theory of science, 2nd edn., Routledge, London.

Bhaskar, R., [1979] 1998, The possibility of naturalism: A philosophical critique of contemporary human sciences, Routledge, London.

Bhaskar, R., 1980, 'Scientific explanation and human emancipation', Radical philosophy 26, 16-28, viewed 20 April 2013, from http://www.philpapers.org/ rec/BHASEA-2

Bhaskar, R., 1989, Reclaiming reality: A critical introduction to contemporary philosophy, Verso, London.

Bhaskar, R., 1993, Dialectic: The pulse of freedom, Routledge, New York, NY.

Bhaskar, R., 2002a, Reflections on meta-reality: Transcendence, emancipation, and everyday life, Sage, London.

Bhaskar, R., 2002b, The philosophy of meta-reality, meta-reality: Creativity, love and freedom, vol. 1, Sage, London.

Bhaskar, R., 2012, From science to emancipation: Alienation and the actuality of enlightenment, Routledge, London.

Bhaskar, R. \& Hartwig, M., 2012, 'Beyond East and West', in M. Hartwig \& J. Morgan (eds.), New studies in critical realism and spirituality, pp. 187-202, Routledge, Oxon.

Bhaskar, R. \& Norrie A., 1998, 'Dialectic and dialectical critical realism', in M. Archer, R. Bhaskar, A. Collier, T. Lawson \& A. Norrie (eds.), Critical realism: Essential readings, pp. 561-640, Routledge, London.

Brown, W., 2009, 'The emergence of causally efficacious mental function', in N. Murphy \& W. Stoeger (eds.), Evolution \& emergence: Systems, organisms, persons, pp. 198-226, Oxford University Press, Oxford.

De Villiers, P.G.R., 2006, 'Spirituality, theology and the critical mind' in, P.G.R. de Villiers, C.E.T. Kourie \& C. Lombaard (eds.), The spirit that moves: Orientation and issues in spirituality, Acta Theologica (Supplementum 8), pp. 99-121, University of issues in spirituality, Acta Theologica
the Free State Press, Bloemfontein.

Gregerson, N., 2009, 'Reduction and emergence in artificial life: A theological appropriation', in N. Murphy \& W. Stoeger (eds.), Evolution \& emergence: Systems, organisms, persons, pp. 284-314, Oxford University Press, Oxford.

Hassoun, N., 2014, Beyond globalization and global justice: Development theory and practice, viewed 12 January 2014, from http://analysis.oxfordjournals.org

Haught, J., 2009, 'Emergence, scientific naturalism, and theology', in N. Murphy \& W. Stoeger (eds.), Evolution \& emergence: Systems, organisms, persons. pp. 284-314 Oxford University Press, Oxford.

Hewlett, M., 2009, 'True to Life? Biological models of origin and evolution', in N. Murphy \& W. Stoeger (eds.), Evolution and emergence: Systems, organisms, persons, pp. 158-172, Oxford University Press, Oxford.

Howard, D., 2009, 'Reduction and emergence in physical sciences: Some lessons from the particle physics and condensed matter debate', in N. Murphy \& W. Stoeger
(eds.), Evolution and emergence: Systems, organisms, persons, pp. 141-157, (eds.), Evolution and emergence:
Oxford University Press, Oxford.

Joas, H., 2000, 'Comment on Göran Therborn', in W. Schelke \& W-H. Krauth (eds.) Paradigms of social change: Modernization, development, transformation, evolution, pp. 73-76, St Martin's Press, New York, NY.

Kourie, C., 2009, 'Spirituality and the university', Verbum et Ecclesia 30(1), 148-173, viewed 30 June 2013, from http://www.ve.org.za/index.php

Luhmann, N., 2013, Introduction to Systems Theory, Polity Press, Cambridge.

Mezirow, J. (ed.), 2000, Learning as transformation: Critical perspectives on a theory in progress, Jossey-Bass, San Francisco, CA.

Murphy, N., 2009, 'Reductionism: How did we fall into it and can we emerge from it?', in N. Murphy \& W. Stoeger (eds.), Evolution \& emergence: Systems, organisms, persons, pp. 19-39, Oxford University Press, Oxford. 
Murphy, M. \& Stoeger, W. (eds.), Evolution \& emergence: Systems, organisms, persons, Oxford University Press, Oxford.

Runciman, W.G., 2000, 'More than a metaphor: The neo-Darwinian paradigm for the explanation of social change', in W. Schelke \& W-H. Krauth (eds.), Paradigms of social change: Modernization, development, transformation, evolution, pp. 307-314, St Martin's Press, New York.

Schelke, W. \& Krauth, W-H. (eds.), 2000, Paradigms of social change: Modernization, development, transformation, evolution, St Martin's Press, New York, NY.

Schreiber, D., (in press), 'Philosophy of meta-reality and post-secular holism: The makings of holiness?

Scott, A., 2009, 'Nonlinear science and the cognitive hierarchy', in N. Murphy \& W. Stoeger (eds.), Evolution and emergence: Systems, organisms, persons, pp. 173-197, Oxford University Press, Oxford.

Segal, J., 1991, Agency and alienation: A theory of human presence, Savage: Rowman \& Littlefield Publishers, New York, NY.
Slote, M., 2007, The ethics of care and empathy, Routledge, London.

Slote, M., 2013, From enlightenment to receptivity: Rethinking our values, Oxford University Press, Oxford. http://dx.doi.org/10.1093/acprof:0so/9780199970704. 001.0001

Stoeger, W., 2009, 'Reductionism and emergence: Implications for interaction of theology with the natural sciences', in N. Murphy \& W. Stoeger (eds.), Evolution \& emergence: Systems, organisms, persons, pp. 229-274, Oxford University Press, Oxford.

Therborn, G., 2000, “Modernization" discourses, their limitations, and their alternatives', in W. Schelke \& W-H. Krauth (eds.), Paradigms of social change: Modernization, development, transformation, evolution, pp. 49-72, St Martin's Press, New York, NY.

Van Gulick, R., 2009, 'Reduction, emergence, and the mind/body problem A philosophic overview', in M. Murphy \& W. Stoeger (eds.), Evolution \& emergence: Systems, organisms, persons, pp. 40-73, Oxford University Press, Oxford. 